\title{
Mechanisms of ST-segment elevation myocardial infarction in patients with atrial fibrillation, prior stenting and long-standing chronic coronary syndrome
}

\author{
Antonio Gabriele Franchina, Dario Calderone, Paolo D’Arrigo, \\ Salvatore Ingala, Rocco Paolo Milluzzo, Antonio Greco, \\ Marco Spagnolo, Corrado Tamburino, Davide Capodanno \\ University of Catania, Italy
}

\begin{abstract}
Background: The optimal antithrombotic regimen for patients with atrial fibrillation $(A F)$ and chronic coronary syndromes beyond 1 year after percutaneous coronary intervention (PCI) is a matter of debate. For these patients, guidelines recommend oral anticoagulation (OAC) alone, but the risk of thrombotic complications remains a concern. The aim of this study was to characterize the incidence, presentation and use of antithrombotic therapy in patients with $A F$, prior stenting $>12$ months and new ST-segment elevation myocardial infarction (STEMI).

Methods: Consecutive patients were selected from an institutional registry over a 3-year period if they matched the following criteria: 1) STEMI undergoing primary PCI; 2) AF; 3) chronic coronary syndrome with prior stenting $>12$ months.

Results: Among 852 consecutive STEMI patients undergoing primary PCI, the prevalence of AF was $4.1 \%$, and $6(0.9 \%)$ patients met all the inclusion criteria. Substantial heterogeneity in antithrombotic treatment for these patients was noted (e.g., OAC alone, OAC plus a single antiplatelet agent, no antithrombotic therapy). In 50\% of patients, the STEMI episode was linked to a previously stented lesion or documented plaque.

Conclusions: This case review illustrates the wide heterogeneity in antithrombotic pharmacotherapy among AF patients presenting with STEMI $>12$ months after PCI. The underlying reason for STEMI is only partly related to disease progression or stent-related events. This finding suggests that multiple mechanisms of recurrence may be advocated, and are not only limited to antithrombotic therapy but may be explained by the natural history of coronary artery disease in remote vessels. (Cardiol J 2020; 27, 1: 8-15)
\end{abstract}

Key words: atrial fibrillation, oral anticoagulation, percutaneous coronary intervention, chronic coronary syndromes, antithrombotic therapy, dual antiplatelet therapy,

ST-segment elevation myocardial infarction

\section{Editorial p. 1}

\section{Introduction}

Based on current guidelines and recent evidence from randomized trials and meta-analyses, patients with atrial fibrillation (AF) and chronic coronary syndromes (CCS) undergoing percutaneous coronary intervention $(\mathrm{PCI})$ should receive oral anticoagulation $(\mathrm{OAC})$ lifelong (preferably with a non-vitamin $\mathrm{K}$ antagonist oral anticoagulant), a P2Y $\mathrm{Y}_{12}$ inhibitor for 12 months (generally clopidogrel), and a variable term of acetylsalicylic acid

Address for correspondence: Davide Capodanno, MD, PhD, Division of Cardiology, A.O.U. "Policlinico-Vittorio Emanuele", University of Catania, Via Santa Sofia 78, Catania, Italy, e-mail: dcapodanno@gmail.com 
(ASA; from a few days to 6 months) depending on the individual balance of bleeding and thrombotic risks $[1,2]$.

According to recent European guidelines, a patient who is event-free for 12 months after PCI was performed, regardless of the initial clinical context for revascularization (e.g., elective or acute coronary syndrome) is described as having a long standing CCS [1]. When these patients have AF, it is broadly accepted that OAC should be continued alone, without concomitant antiplatelet therapy $[1,3,4]$. The AFIRE trial recently showed that adding ASA to OAC monotherapy exposes patients to an unacceptable and possibly life-threatening increased risk of bleeding [5]. However, some physicians are afraid that routinely stopping any antiplatelet therapy would expose some patients to the risk of catastrophic consequences that outweigh the risk of bleeding, e.g., those with prior PCI of the left main or the proximal left anterior descending artery (LAD). Current guidelines for CCS, published before the AFIRE trial, allow for the combination of an antiplatelet with $\mathrm{OAC}$ in selected circumstances [1].

When patients with AF, prior PCI and longstanding CCS present with ST-segment elevation myocardial infarction (STEMI), the question arises on the mechanisms for the new event, which may include very late stent thrombosis, progression of coronary artery disease (CAD), and lack of adequate antithrombotic protection. According to available research, there are no studies characterizing the angiographic presentation and use of antithrombotic therapy before and at the time of STEMI in patients with AF, prior PCI or longstanding CCS. A better understanding of these correlations is meaningful to inform the rationale for future studies of dual antithrombotic therapy at 12 months or longer from PCI.

Given this background, it is herein reported a review of STEMI cases with the following objectives: 1) defining the frequency of STEMI as the consequence of stent thrombosis or CAD progression by matching the angiographic presentation before and at the time of the STEMI episode; 2) identifying potential causes of pharmacological failure and areas for improvement by describing the antithrombotic regimen before, (time 0 [T0]) and at the time of STEMI presentation (time 1 [T1]).

\section{Methods}

A total of 852 consecutive STEMI patients undergoing primary PCI between December 2015 and

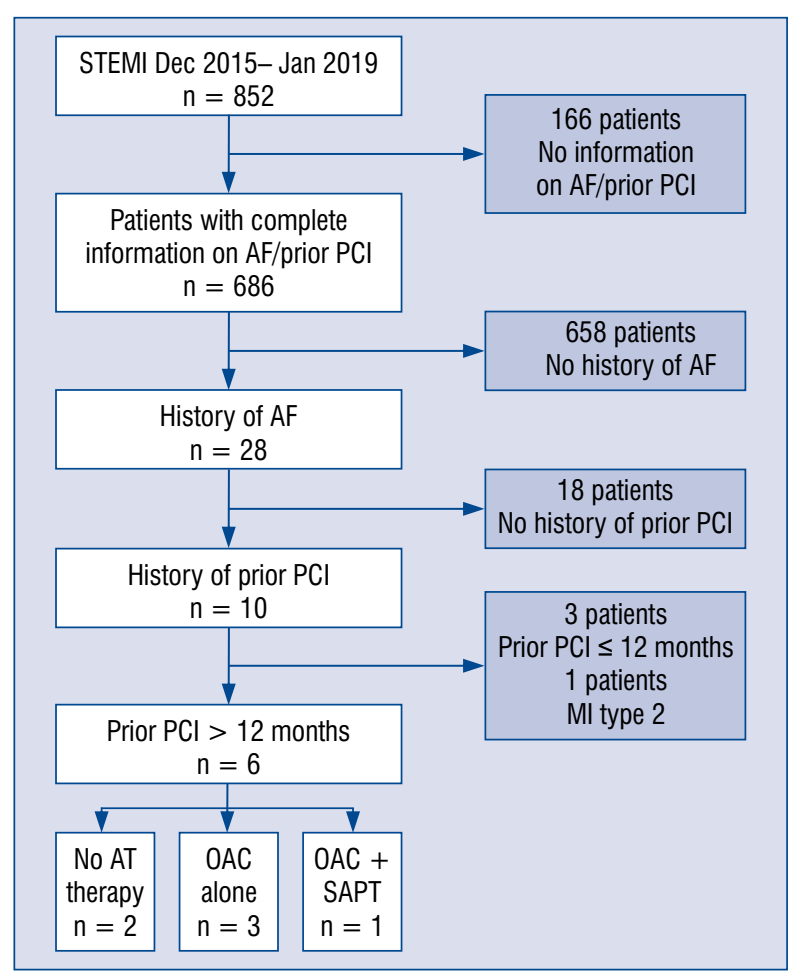

Figure 1. Flow diagram of patients selected according to pre-specified inclusion and exclusion criteria; AF atrial fibrillation; $\mathrm{AT}$ - antithrombotic; $\mathrm{MI}$ - myocardial infarction; OAC - oral anticoagulation; $\mathrm{PCl}$ - percutaneous coronary intervention; SAPT — single antiplatelet therapy; STEMI - ST-segment elevation myocardial infarction.

January 2019 were retrospectively analyzed from the documented institutional registry. The screening flow chart is reported in Figure 1. Patients were included if they presented with $\mathrm{AF}$ and if a prior PCI with implantation of at least a coronary stent was performed at least 12 months before STEMI presentation. A total of 166 (19\%) patients were excluded because no complete information was available on AF status, antithrombotic regimen or prior PCI. Of the remaining subset, $28(4.1 \%)$ patients presented with $\mathrm{AF}$ at the time of STEMI. Of these, $6(21.4 \%)$ patients presented with a prior PCI performed at least 12 months earlier (i.e., $0.9 \%$ of the analyzable STEMI cohort). For these cases, clinical charts, angiographic outcomes and antithrombotic therapy at the time of the prior PCI (T0) and at the time of STEMI (T1) were reviewed in detail. Case summaries of the 6 patients included are provided below. Basic descriptive statistics for baseline characteristics and outcomes of interest (very late stent thrombosis, CAD progression, withdrawal of antithrombotic therapy) were cal- 
Table 1. Baseline clinical characteristics at the time of ST-segment elevation myocardial infarction presentation.

\begin{tabular}{|c|c|c|c|c|c|c|}
\hline & Case no. 1 & Case no. 2 & Case no. 3 & Case no. 4 & Case no. 5 & Case no. 6 \\
\hline Age [years] & 78 & 61 & 62 & 56 & 71 & 69 \\
\hline Gender & Male & Male & Male & Male & Male & Male \\
\hline BMI & NA & 30.1 & 33 & 27.1 & 25 & 37.2 \\
\hline \multicolumn{7}{|c|}{ Cardiovascular risk factors: } \\
\hline Hypertension & Yes & Yes & Yes & Yes & Yes & Yes \\
\hline Diabetes & No & Yes & Yes & Yes & Yes & Yes \\
\hline Dyslipidemia & Yes & Yes & No & Yes & Yes & No \\
\hline Current smoker & Yes & Yes & Yes & No & No & No \\
\hline Former smoker & No & No & No & Yes & Yes & Yes \\
\hline \multicolumn{7}{|l|}{ Clinical history: } \\
\hline Prior stroke & No & No & No & Yes & No & No \\
\hline PAD & No & Yes & No & No & No & No \\
\hline CKD & No & No & No & Yes & No & No \\
\hline Prior $\mathrm{PCl}$ & Yes & Yes & Yes & Yes & Yes & Yes \\
\hline Prior CABG & No & No & No & Yes & No & No \\
\hline Prior MVR & No & Yes & No & Yes & No & Yes \\
\hline Other valvular disease & No & No & No & No & No & No \\
\hline Pattern of $A F$ & Paroxysmal & Paroxysmal & Permanent & Permanent & Permanent & Permanent \\
\hline AF at presentation & No & No & Yes & Yes & Yes & Yes \\
\hline LVEF [\%] & 45 & 43 & 42 & NA & 28 & 37 \\
\hline
\end{tabular}

$\mathrm{AF}$ - atrial fibrillation; BMI — body mass index; CABG — coronary artery bypass grafting; CKD — chronic kidney disease (defined as glomerular filtration rate $<60 \mathrm{~mL} / \mathrm{min}$ ); LVEF — left ventricular ejection fraction; MVR - mechanical valve replacement; NA — not available; PAD peripheral artery disease; $\mathrm{PCl}$ - percutaneous coronary intervention

culated with the Statistical Package for Social Sciences (SPSS) v. 24.0 (IBM Corporation, NY, USA). Results are reported as count and percentage for binary variables and mean \pm standard deviation or median (interquartile range) for continuous variables, as appropriate based on normality distribution according to the Kolmogorov-Smirnov test.

\section{Results}

Baseline characteristics of patients included in this case series as determined at $\mathrm{T} 1$ are listed in Table 1 . All patients were male, the mean age was $66 \pm 8$ years, the mean $\mathrm{CHA}_{2} \mathrm{DS}_{2}$-VASc score was $4.0 \pm 0.9$, and the mean HAS-BLED score was $0.8 \pm$ \pm 0.8 . All patients had a reduced left ventricular ejection fraction, and 5 out of $6(83 \%)$ presented with diabetes mellitus and a history of a prior acute coronary syndrome. Summarized in Tables 2 and 3 are the procedural details of $\mathrm{PCI}$ at $\mathrm{T} 0$ and $\mathrm{T} 1$, respectively. The mean time from the prior PCI to STEMI presentation (i.e., T1-T0) was $6.5 \pm 4.8$ years. Table 4 summarizes antithrombotic therapy at $\mathrm{T} 1$ (admission and discharge). Two patients out of $6(33.3 \%)$ were not on OAC despite their $\mathrm{CHA}_{2} \mathrm{DS}_{2}$-VASc score and current, relevant guideline recommendations.

Overall, very late stent thrombosis occurred in 2 out of 6 patients (33.3\%). In another patient $(16.7 \%)$, progression of a documented untreated plaque was the likely mechanism of STEMI at play. Recent withdrawal of antithrombotic therapy was documented in $2(33.3 \%)$ patients. One (16.7\%) patient had very late stent thrombosis in the context of recent withdrawal of antithrombotic therapy. Case summaries for all 6 patients are reported below.

Case no. 1. A 78-year-old man with paroxysmal AF underwent stent implantation of a ramus in 2003 due to unstable angina (T0). The other vessels were free of disease with the exception of the mid-proximal right coronary artery (RCA), which presented with a $50 \%$ stenosis left untreated. In 2006 and 2010 he underwent angiographic follow-up that showed the relative patency of the stent, with subcritical narrowing $(<50 \%)$ due to 
Table 2. Procedural details of last percutaneous coronary intervention before current ST-segment elevation myocardial infarction (STEMI) presentation.

\begin{tabular}{|c|c|c|c|c|c|c|}
\hline & $\begin{array}{l}\text { Case } \\
\text { no. } 1\end{array}$ & $\begin{array}{l}\text { Case } \\
\text { no. } 2\end{array}$ & $\begin{array}{l}\text { Case } \\
\text { no. } 3\end{array}$ & $\begin{array}{l}\text { Case } \\
\text { no. } 4\end{array}$ & $\begin{array}{l}\text { Case } \\
\text { no. } 5\end{array}$ & $\begin{array}{l}\text { Case } \\
\text { no. } 6\end{array}$ \\
\hline Time from last $\mathrm{PCl}$ to $\mathrm{T}{ }^{*}$ [years] & 14 & 2 & 7 & 3 & 3 & 10 \\
\hline Clinical presentation & ACS & ACS & ACS & Stable CAD & ACS & ACS \\
\hline Stented vessel & Ramus & Mid LAD & OM & Prox RCA & Mid LAD & Diagonal \\
\hline Number of implanted stents & NA & NA & NA & 1 & 1 & 1 \\
\hline $\begin{array}{l}\text { Other lesions } \geq 50 \% \text { in remote } \\
\text { vessels }\end{array}$ & $50 \%$ mid RCA & No & No & No & No & No \\
\hline $\begin{array}{l}\text { Time from last coronary } \\
\text { angiography to } T 1^{*} \text { [years] }\end{array}$ & 7 & 2 & 5 & 2 & 1 & 9 \\
\hline Lesions $\geq 50 \%$ at follow-up & $\begin{array}{l}50 \% \text { ISR ramus; } \\
50 \% \text { mid } \mathrm{RCA}\end{array}$ & - & NA & - & $50 \%$ OM & - \\
\hline
\end{tabular}

*T1 refers to the time of primary PCI for STEMI. ACS - acute coronary syndrome; CAD — coronary artery disease; ISR — in-stent restenosis; $\mathrm{LAD}$ - left anterior descending; $\mathrm{NA}$ - not available; $\mathrm{OM}$ - obtuse marginal; $\mathrm{PCI}$ - percutaneous coronary intervention; RCA — right coronary artery

Table 3. Procedural details of primary percutaneous coronary intervention (PCl) at the time of ST-segment elevation myocardial infarction presentation.

\begin{tabular}{|c|c|c|c|c|c|c|}
\hline & $\begin{array}{l}\text { Case } \\
\text { no. } 1\end{array}$ & $\begin{array}{l}\text { Case } \\
\text { no. } 2\end{array}$ & $\begin{array}{l}\text { Case } \\
\text { no. } 3\end{array}$ & $\begin{array}{l}\text { Case } \\
\text { no. } 4\end{array}$ & $\begin{array}{l}\text { Case } \\
\text { no. } 5\end{array}$ & $\begin{array}{l}\text { Case } \\
\text { no. } 6\end{array}$ \\
\hline Date & $\begin{array}{l}\text { April } \\
2017\end{array}$ & $\begin{array}{c}\text { November } \\
2017\end{array}$ & $\begin{array}{c}\text { November } \\
2018\end{array}$ & $\begin{array}{c}\text { September } \\
2017\end{array}$ & $\begin{array}{c}\text { January } \\
2019\end{array}$ & $\begin{array}{l}\text { March } \\
2018\end{array}$ \\
\hline Culprit lesion & Mid-prox RCA & Diagonal & LMCA & Mid LAD & Prox RCA & Diagonal \\
\hline Stent thrombosis & No & Yes & No & No & No & Yes \\
\hline $\begin{array}{l}\text { Other lesions } \geq 50 \% \\
\text { in remote vessels }\end{array}$ & $\begin{array}{l}50 \% \text { ISR } \\
\text { ramus }\end{array}$ & $100 \%$ LCx & $\begin{array}{l}100 \% \text { mid } \\
\text { LAD }\end{array}$ & $\begin{array}{l}100 \% \text { LIMA- } \\
\text {-LAD; } 70 \% \\
\text { mid RCA }\end{array}$ & $\begin{array}{l}100 \% \mathrm{PL} \\
50 \% \mathrm{OM}\end{array}$ & $\begin{array}{c}100 \% \text { LAD; } \\
100 \% \\
\text { diagonal }\end{array}$ \\
\hline $\mathrm{PCl}$ procedure & $\begin{array}{l}3 \text { BMS on } \\
\text { the RCA }\end{array}$ & $\begin{array}{l}1 \text { DES on } \\
\text { the diagonal }\end{array}$ & $\begin{array}{l}1 \text { DES on } \\
\text { the LMCA }\end{array}$ & $\begin{array}{l}1 \text { DES on } \\
\text { the LAD; } \\
1 \text { DES on } \\
\text { the mid RCA }\end{array}$ & $\begin{array}{l}\text { POBA on the } \\
\text { prox RCA; } \\
1 \text { DES on } \\
\text { the PL }\end{array}$ & $\begin{array}{l}1 \text { DES on the } \\
\text { prox LAD; } \\
\text { POBA on } \\
\text { the diagonal }\end{array}$ \\
\hline $\begin{array}{l}\mathrm{P}^{2} \mathrm{Y}_{12 \text {-inhibitors }} \\
\text { loading dose }\end{array}$ & $\begin{array}{l}\text { ticagrelor } \\
180 \mathrm{mg}\end{array}$ & $\begin{array}{l}\text { clopidogrel } \\
600 \mathrm{mg}\end{array}$ & $\begin{array}{l}\text { clopidogrel } \\
600 \mathrm{mg}\end{array}$ & $\begin{array}{c}\text { ticagrelor } \\
180 \mathrm{mg}\end{array}$ & $\begin{array}{l}\text { clopidogrel } \\
600 \mathrm{mg}\end{array}$ & $\begin{array}{c}\text { ticagrelor } \\
180 \mathrm{mg}\end{array}$ \\
\hline $\begin{array}{l}\text { i.v. antithrombotic drugs } \\
\text { administered before or } \\
\text { during the procedure }\end{array}$ & $\begin{array}{c}\text { UFH; } \\
\text { abciximab }\end{array}$ & UFH & UFH & UFH & UFH & UFH \\
\hline
\end{tabular}

BMS - bare metal stent; DES — drug eluting stent; ISR — in-stent restenosis; iv, intravenous; LAD — left anterior descending; LCx — left circumflex; LIMA — left internal mammary artery; LMCA — left main coronary artery; OM — obtuse marginal; PCI — percutaneous coronary intervention; PL — posterolateral; POBA — plain old balloon angioplasty; RCA — right coronary artery; UFH — unfractionated heparin

in-stent neointimal proliferation and no disease progression at the level of the RCA and the LAD. In 2017 (T1), he qualified for primary PCI due to an inferior STEMI. At entry, the patient was not taking any antithrombotic drug, including OAC. He mentioned a deliberate discontinuation of ASA approximately 2 weeks earlier. Coronary angiography showed evidence of a large thrombus at the level of the occluded mid-proximal RCA. He underwent primary PCI with implantation of
3 meshed bare metal stents. The stent of the ramus presented with the same degree of narrowing already shown in 2010, and the LAD presented with a new $40 \%$ stenosis of the proximal segment. The patient, presenting with a $\mathrm{CHA}_{2} \mathrm{DS}_{2}$-VASc score of 4 and a HAS-BLED score of 1 at T1, was discharged on dual antiplatelet therapy (DAPT) with ASA $100 \mathrm{mg} /$ die and ticagrelor $90 \mathrm{mg}$ bid.

Case no. 2. A 61-year-old man with paroxysmal $\mathrm{AF}$ and prior aortic valve replacement with 
Table 4. Antithrombotic (AT) therapy and ischemic/hemorrhagic risk (T1).

\begin{tabular}{|c|c|c|c|c|c|c|}
\hline & $\begin{array}{l}\text { Case } \\
\text { no. } 1\end{array}$ & $\begin{array}{l}\text { Case } \\
\text { no. } 2\end{array}$ & $\begin{array}{l}\text { Case } \\
\text { no. } 3\end{array}$ & $\begin{array}{l}\text { Case } \\
\text { no. } 4\end{array}$ & $\begin{array}{l}\text { Case } \\
\text { no. } 5\end{array}$ & $\begin{array}{l}\text { Case } \\
\text { no. } 6\end{array}$ \\
\hline AT therapy at admission & $\begin{array}{l}\text { No AT } \\
\text { therapy }\end{array}$ & $\begin{array}{l}\text { No AT } \\
\text { therapy }\end{array}$ & $\begin{array}{l}\text { OAC } \\
\text { alone }\end{array}$ & $\begin{array}{l}\text { OAC } \\
\text { alone }\end{array}$ & OAC plus SAPT & $\begin{array}{l}\text { OAC } \\
\text { alone }\end{array}$ \\
\hline Specific AT therapy & - & - & $\begin{array}{l}\text { dabigatran } \\
110 \text { mg bid }\end{array}$ & warfarin $5 \mathrm{mg}$ & $\begin{array}{c}\text { dabigatran } \\
110 \mathrm{mg} \text { bid; } \\
\text { ASA } 75 \mathrm{mg} / \text { die }\end{array}$ & $\begin{array}{l}\text { warfarin } \\
5 \mathrm{mg}\end{array}$ \\
\hline $\begin{array}{l}\mathrm{CHA}_{2} \mathrm{DS}_{2} \text {-VASc score } \\
\text { at entry }\end{array}$ & 4 & 3 & 3 & 5 & 5 & 4 \\
\hline HAS-BLED score at entry & 1 & 0 & 0 & 1 & 2 & 1 \\
\hline $\begin{array}{l}\text { AT therapy prescribed } \\
\text { at discharge }\end{array}$ & $\begin{array}{c}\text { DAPT } \\
\text { (ASA and } \\
\text { ticagrelor) }\end{array}$ & $\begin{array}{l}\text { DAPT (ASA } \\
\text { and clopi- } \\
\text { dogrel) plus } \\
\text { acenocu- } \\
\text { marol } 4 \mathrm{mg}\end{array}$ & $\begin{array}{l}\text { DAPT (ASA } \\
\text { and clopi- } \\
\text { dogrel) plus } \\
\text { dabigatran } \\
110 \mathrm{mg} \text { bid }\end{array}$ & $\begin{array}{l}\text { NA (patient } \\
\text { transferred } \\
\text { to another } \\
\text { ICU) }\end{array}$ & $\begin{array}{l}\text { DAPT (ASA and } \\
\text { clopidogrel) plus } \\
\text { dabigatran } \\
110 \mathrm{mg} \text { bid }\end{array}$ & $\begin{array}{l}\text { DAPT (ASA } \\
\text { and clopi- } \\
\text { dogrel) plus } \\
\text { warfarin } \\
5 \mathrm{mg}\end{array}$ \\
\hline
\end{tabular}

ASA — acetylsalicylic acid (i.e. aspirin); DAPT — dual anti-platelet therapy; ICU — intensive care unit; OAC — oral anticoagulant; SAPT — single antiplatelet therapy

a mechanical prosthesis in 2005 , underwent PCI and drug-eluting stent (DES) implantation of the mid LAD in 2015 due to unstable angina (T0). The other vessels were free of disease. In 2017, he qualified for primary PCI due to an anterior STEMI (T1). At entry, the patient was not on antithrombotic drugs due to discontinuation of OAC 3 days earlier due to a planned prostate biopsy. The coronary angiography showed a thrombotic stenosis of the ostium of the second diagonal, at the level of the LAD stent. The patient underwent primary PCI of the diagonal with implantation of a DES at the bifurcation level. The patient, presenting with a $\mathrm{CHA}_{2} \mathrm{DS}_{2}$-VASc score of 3 and a HAS-BLED score of 0 at T1, was discharged on DAPT (ASA $100 \mathrm{mg} / \mathrm{die}$ and clopidogrel $75 \mathrm{mg} /$ die) plus OAC.

Case no. 3. A 62-year-old man with permanent AF underwent PCI with DES implantation of the first obtuse marginal in 2011 due to an inferior STEMI (T0). The LAD presented a chronic total occlusion in the mid portion. In 2018, he qualified for primary PCI due to a new anterior STEMI (T1). At entry, the patient was on OAC with dabigatran $110 \mathrm{mg}$ bid. Coronary angiography showed a complicated atherosclerotic plaque of the left main, with signs of rupture and dissection. Primary PCI of the left main with implantation of a DES was performed. The LAD was chronically occluded and the left circumflex artery presented two new intermediate stenoses at the proximal and distal segments, whereas the stent in the first obtuse marginal was patent. The patient, presenting with a $\mathrm{CHA}_{2} \mathrm{DS}_{2}$-VASc score of 3 and a HAS-BLED score of 0 at the time of STEMI, was discharged on DAPT (ASA $100 \mathrm{mg} /$ die and clopidogrel $75 \mathrm{mg} /$ die) plus dabigatran $110 \mathrm{mg}$ bid.

Case no. 4. A 56-year-old man with permanent $\mathrm{AF}$ and a history of ischemic stroke, underwent elective stent implantation of the RCA in 2014 (T0), 1 month after mitral and aortic valve replacement with mechanical prostheses and concomitant bypass of the LAD with the left internal mammary artery. In 2017 (T1), he qualified for primary PCI because of an anterior STEMI complicated by defibrillated ventricular tachycardia. At entry, the patient was on OAC only. The coronary angiography showed a subocclusive stenosis of the mid LAD with occluded left internal mammary artery and a critical stenosis of the mid RCA. The patient underwent primary PCI with implantation of a DES on the mid segment of the LAD and another DES in the mid segment of the RCA during the same procedure. After the intervention, the patient was brought back to the intensive care unit of another hospital, where he died a few days later for unknown reasons. His $\mathrm{CHA}_{2} \mathrm{DS}_{2}-\mathrm{VASc}$ and HAS-BLED scores at T 1 were 5 and 1 , respectively.

Case no. 5. A 71-year-old man with permanent $\mathrm{AF}$ underwent DES implantation of the mid segment of the LAD in 2016 due to a non-STEMI (T0). The patient underwent a follow-up coronary angiography in December 2018, which showed mild in-stent restenosis $(<50 \%)$ of the LAD and a new $50-70 \%$ stenosis of the obtuse marginal, whereas the RCA was free of disease. In January 2019 (T1), he presented with an inferior STEMI. 
At entry the patient was on antithrombotic therapy with ASA plus OAC (dabigatran $110 \mathrm{mg}$ bid). The coronary angiography showed evidence of a thrombotic occlusion of the proximal RCA. Primary PCI was performed with plain old balloon angioplasty of the proximal RCA segment and implantation of $1 \mathrm{DES}$ at the level of the posterolateral branch. The patient, presenting with a $\mathrm{CHA}_{2} \mathrm{DS}_{2}$-VASc score of 5 and an HAS-BLED score of 2 at T1, was discharged on DAPT (ASA $100 \mathrm{mg} /$ die, clopidogrel $75 \mathrm{mg}$ /die) plus OAC with dabigatran $110 \mathrm{mg}$ bid.

Case no. 6. A 69-year-old man with permanent $\mathrm{AF}$ underwent DES implantation of the first diagonal in 2008 (T0). In 2009 he underwent aortic valve replacement with a mechanical prosthesis. In 2018, he presented with an anterior STEMI (T1). At entry, the patient was on OAC with warfarin. Coronary angiography showed an occlusion of the first diagonal and the proximal segment of the LAD due to a relevant thrombus. Primary PCI was performed with the implantation of $1 \mathrm{DES}$ on the proximal segment of the LAD and plain old balloon angioplasty of the diagonal. The patient, presenting with a $\mathrm{CHA}_{2} \mathrm{DS}_{2}-\mathrm{VASc}$ score of 4 and an HAS-BLED score of 1 at the time of STEMI, was discharged on DAPT (ASA $100 \mathrm{mg} /$ die and clopidogrel $75 \mathrm{mg} /$ die) plus OAC.

\section{Discussion}

Among patients with established CAD, the prevalence of concurrent $\mathrm{AF}$ is estimated at $6-8 \%$ $[6,7]$. Yet, $\mathrm{AF}$ is more frequently encountered in the setting of STEMI, encompassing approximately $14 \%$ of patients [8], and a review from Gorenek et al. [9] reported that in about $2.5-4.4 \%$ of STEMI patients the arrhythmia existed prior to hospital admission. This is consistent with the present findings. In fact, among 852 STEMI patients screened for the purpose of the current study, $4.1 \%$ had history of AF. Of the 10 patients with AF and a history of prior PCI, 6 (60\%) had a long-standing CCS according to 2019 guidelines of the European Society of Cardiology [1].

For $\mathrm{AF}$ patients such as those included in this case series, current European guidelines recommend chronic OAC alone [1]. This recommendation is supported by registry data [10-12], and has been recently reinforced by the results of two randomized trials $[5,13]$. In the OAC-ALONE trial, the efficacy and safety of OAC monotherapy compared with dual antithrombotic therapy with OAC and an antiplatelet was investigated in patients with $\mathrm{AF}$ and long-standing CCS (i.e., beyond 1 year after coronary stenting) [13]. The trial failed to establish non-inferiority of OAC alone likely due to low power because patient enrollment was prematurely terminated due to slow recruitment. In the AFIRE trial, rivaroxaban monotherapy was non-inferior to combination therapy with ASA for efficacy and was superior for safety in a similar, larger population [5]. The trial was discontinued early because of increased mortality in the combination-therapy group. While the superior safety of using one rather than two antithrombotic agents is obvious, the efficacy of such an approach in preventing coronary events is less established. Indeed, goodquality $\mathrm{OAC}$ in patients with $\mathrm{AF}$ is associated with lower risk of myocardial infarction, which makes concomitant use of antiplatelet agents of uncertain added utility [14, 15]. However, a systematic review of 21 observational studies and 10 clinical trials suggests that AF patients with CCS have a substantial annual residual risk of myocardial infarction despite OAC [16].

After 12 months from PCI, antiplatelet agents are still used by some physicians in combination with $\mathrm{OAC}$, due to concerns of residual thrombotic risk [17, 18]. Current guidelines endorse this practice with a class IIb recommendation [1]. Conversely, there is also a proportion of patients with $\mathrm{AF}$ who do not receive adequate prevention for thromboembolism in daily practice, as also reinforced by the observation that at least $15 \%$ to $30 \%$ of AF patients are treated with ASA only, or do not receive any antithrombotic treatment $[19,20]$. As a matter of fact, substantial heterogeneity has been reported in antithrombotic treatment regimens for AF patients with long-standing CCS and prior PCI [17]. This uncertainty is also reflected in the current series: 3 patients (case no. 3 , case no. 4 and case no. 6) were on OAC therapy alone (yet, 2 had a mechanical prosthesis); 1 patient (case no. 5) was on OAC plus a single antiplatelet agent; 2 patients (case no. 1 and case no. 2) were on no antithrombotic therapy. Despite these differences, all patients presented with STEMI, suggesting the existence of other explanations that go beyond lack of optimal antithrombotic protection. Indeed, in case no. 1, STEMI developed on a plaque previously left untreated in a patient with no antithrombotic therapy on board and recent ASA disruption. In case no. 2, the patient presented with stent thrombosis, was not on antithrombotic therapy and had recently interrupted OAC. In these two cases, withdrawal of antithrombotic protection cannot be excluded. In contrast, in case no. 6 , the patient was on $\mathrm{OAC}$ with warfarin (with uncertain time in 
the therapeutic range) and thrombosis occurred 10 years after stent implantation with no apparent explanation. Whether the addition of an antiplatelet agent would have prevented this very late event is speculative at best. In aggregate, only $2(33.3 \%)$ cases were related to prior PCI (i.e., very late stent thrombosis) and only 1 (16.7\%) case was related to a previously-described untreated lesion. In all other cases there was an inability to correlate the occurrence of STEMI with any previously documented angiographic substrate and other causes can be inferred, such as plaque rupture in segments previously free from disease and/or inadequate control of cardiovascular risk factors (e.g., $83 \%$ of patients were diabetics).

The results of this case review are exploratory and should be carefully interpreted with a note of caution in the context of the following limitations. Firstly, the small sample size prevented drawing robust conclusions on the issue of antithrombotic therapy for AF patients with long-standing CCS and prior stenting. Indeed, this is an area of uncertainty where larger studies are lacking. Secondly, 166 patients out of 852 (i.e., almost $20 \%$ of the STEMI patients in the documented database) were excluded upfront due to incomplete information. As such, the chance of selection bias cannot completely be ruled out.

\section{Conclusions}

Among patients presenting with STEMI, a history of AF and prior PCI $>12$ months is infrequent. Although these patients were theoretically candidates for OAC alone prior to the STEMI episode, substantial heterogeneity in antithrombotic regimens at entry was observed in real practice. Stent thrombosis or CAD progression explained only half of the STEMI episodes and a clear association with lack of antithrombotic therapy protection could not be inferred. Larger studies are needed to define optimal strategies for STEMI prevention in $\mathrm{AF}$ patients with prior stenting and long-standing CCS.

\section{Conflict of interest: None declared}

\section{References}

1. Knuuti J, Wijns W, Saraste A, et al. 2019 ESC Guidelines for the diagnosis and management of chronic coronary syndromes The Task Force for the diagnosis and management of chronic. Eur Heart J. 2019; 00: 1-71, doi: 10.1093/eurheartj/ehz425.

2. Capodanno D, Huber K, Mehran R, et al. Management of Antithrombotic Therapy in Atrial Fibrillation Patients Undergo- ing PCI: JACC State-of-the-Art Review. J Am Coll Cardiol. 2019; 74(1): 83-99, doi: 10.1016/j.jacc.2019.05.016, indexed in Pubmed: 31272556.

3. Lip GYH, Collet J-P, Haude M, et al. 2018 Joint European consensus document on the management of antithrombotic therapy in atrial fibrillation patients presenting with acute coronary syndrome and/or undergoing percutaneous cardiovascular interventions: a joint consensus document of the Europe. Europace. 2019; 21(2): 192-193, doi: 10.1093/europace/euy174.

4. Angiolillo DJ, Goodman SG, Bhatt DL, et al. Antithrombotic Therapy in Patients With Atrial Fibrillation Treated With Oral Anticoagulation Undergoing Percutaneous Coronary Intervention. Circulation. 2018; 138(5): 527-536, doi: 10.1161/CIRCULATIONAHA.118.034722, indexed in Pubmed: 30571525.

5. Yasuda S, Kaikita K, Akao M, et al. AFIRE Investigators. Antithrombotic therapy for atrial fibrillation with stable coronary disease. N Engl J Med. 2019; 381(12): 1103-1113, doi: 10.1056/ NEJMoa1904143, indexed in Pubmed: 31475793.

6. Kirchhof P, Benussi S, Kotecha D, et al. 2016 ESC Guidelines for the management of atrial fibrillation developed in collaboration with EACTS. Eur Heart J. 2016; 37(38): 2853-2853, doi: 10.1093/eurheartj/ehw210.

7. Valgimigli M, Bueno H, Byrne RA, et al. 2017 ESC focused update on dual antiplatelet therapy in coronary artery disease developed in collaboration with EACTS. Eur J Cardio-thoracic Surg. 2018; 53(1): 34-78, doi: 10.1093/eurheartj/ehx419.

8. Saczynski JS, McManus D, Zhou Z, et al. Trends in atrial fibrillation complicating acute myocardial infarction. Am J Cardiol. 2009; 104(2): 169-174, doi: 10.1016/j.amjcard.2009.03.011, indexed in Pubmed: 19576341.

9. Gorenek B, Kudaiberdieva G. Atrial fibrillation in acute ST-elevation myocardial infarction: clinical and prognostic features. Curr Cardiol Rev. 2012; 8(4): 281-289, doi: 10.2174/157340312803760857, indexed in Pubmed: 22920476.

10. Lamberts M, Gislason GH, Lip GYH, et al. Antiplatelet therapy for stable coronary artery disease in atrial fibrillation patients taking an oral anticoagulant: a nationwide cohort study. Circulation. 2014; 129(15): 1577-1585, doi: 10.1161/CIRCULATIONAHA.113.004834, indexed in Pubmed: 24470482.

11. Seivani Y, Abdel-Wahab M, Geist V, et al. Long-term safety and efficacy of dual therapy with oral anticoagulation and clopidogrel in patients with atrial fibrillation treated with drug-eluting stents. Clin Res Cardiol. 2013; 102(11): 799-806, doi: 10.1007/s00392013-0592-z, indexed in Pubmed: 23771774.

12. Hamon M, Lemesle G, Tricot O, et al. Incidence, source, determinants, and prognostic impact of major bleeding in outpatients with stable coronary artery disease. J Am Coll Cardiol. 2014; 64(14): 1430-1436, doi: 10.1016/j.jacc.2014.07.957, indexed in Pubmed: 25277612.

13. Matsumura-Nakano Y, Shizuta S, Komasa A, et al. OAC-ALONE Study Investigators. Open-Label Randomized Trial Comparing Oral Anticoagulation With and Without Single Antiplatelet Therapy in Patients With Atrial Fibrillation and Stable Coronary Artery Disease Beyond 1 Year After Coronary Stent Implantation. Circulation. 2019; 139(5): 604-616, doi: 10.1161/CIRCULATIONAHA.118.036768, indexed in Pubmed: 30586700.

14. Olsson SB. Executive Steering Committee of the SPORTIF III Investigators. Stroke prevention with the oral direct thrombin inhibitor ximelagatran compared with warfarin in patients with non-valvular atrial fibrillation (SPORTIF III): randomised con- 
trolled trial. Lancet. 2003; 362(9397): 1691-1698, doi: 10.1016/ s0140-6736(03)14841-6, indexed in Pubmed: 14643116.

15. Pastori D, Pignatelli P, Saliola M, et al. Inadequate anticoagulation by Vitamin K Antagonists is associated with Major Adverse Cardiovascular Events in patients with atrial fibrillation. Int J Cardiol. 2015; 201: 513-516, doi: 10.1016/j.ijcard.2015.08.054, indexed in Pubmed: 26318513.

16. Violi F, Soliman EZ, Pignatelli P, et al. Atrial fibrillation and myocardial infarction: a systematic review and appraisal of pathophysiologic mechanisms. J Am Heart Assoc. 2016; 5(5), doi: 10.1161/JAHA.116.003347, indexed in Pubmed: 27208001.

17. Ancedy Y, Lecoq C, Saint Etienne C, et al. Antithrombotic management in patients with atrial fibrillation undergoing coronary stent implantation: What is the impact of guideline adherence? Int J Cardiol. 2016; 203: 987-994, doi: 10.1016/j.ijcard.2015.11.090, indexed in Pubmed: 26625327.
18. Ono F, Tanaka S, Nakao Y, et al. Utilization of Anticoagulant and Antiplatelet Agents Among Patients With Atrial Fibrillation Undergoing Percutaneous Coronary Intervention: Retrospective Cohort Study Using a Nationwide Claims Database in Japan. Circ J. 2018; 82(2): 361-368, doi: 10.1253/circj.cj-17-0547.

19. Kirchhof P, Ammentorp B, Darius H, et al. Management of atrial fibrillation in seven European countries after the publication of the 2010 ESC Guidelines on atrial fibrillation: primary results of the PREvention oF thromboemolic events--European Registry in Atrial Fibrillation (PREFER in AF). Europace. 2014; 16(1): 6-14, doi: 10.1093/europace/eut263, indexed in Pubmed: 24084680.

20. Lip GYH, Laroche C, Dan GA, et al. ,Real-world' antithrombotic treatment in atrial fibrillation: The EORP-AF pilot survey. Am J Med. 2014; 127(6): 519-529.e1, doi: 10.1016/j.amjmed.2013.12.022, indexed in Pubmed: 24486284. 